\title{
Utilização de creme de papaína e extrato liofilizado das raízes de salsa (Petroselinum crispum) contra Escherichia coli multirresistente em abscesso em equino
}

\author{
Use of Papain Cream and Lyophilized Parsley Root Extract (Petroselinum crispum) \\ against Multi-Resistant Escherichia coli in Equine Abscess
}

\author{
Carla Faria Orlandini', André Giarola Boscarato', Rodrigo Assunção Moura', Patrícia Sapateiro²,

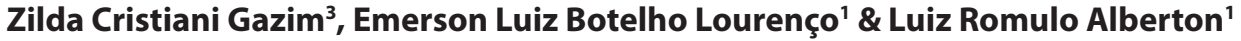

\begin{abstract}
Background: Due to the bacterial resistance to conventional antibiotics, studies on natural products with antibacterial or bactericidal activity are becoming more and more frequent. Among multi-resistant bacteria, Escherichia coli is a producer of extended-spectrum beta-lactamase (ESBL). Papain, coming from papaya latex (Carica papaya), stands out for its capacity to degrade the devitalized tissue that delays the healing process. Parsley (Petroselinum crispum) has been studied, mainly for its diuretic, antioxidant and antimicrobial properties. The aim of this work was to report the use of these two phytotherapic agents in an equine presenting abscess infected by multi-resistant ESBL producing E. coli.

Case: A four and a half year old male neutered equine weighing $400 \mathrm{~kg}$ of undefined race (SRD) was admitted to the Veterinary Hospital of the Paranaense University (UNIPAR), presenting an increased volume on the left side of the middle third of the neck, one year ago, probably due to an intramuscular injection in the splenius muscle performed by the animal's owner, who did not remember which drug had been applied. Physical examination revealed a characteristic abscess lesion that involved the subcutaneous and muscular tissue of approximately $10 \mathrm{~cm}$ in diameter, and presented a fistulous trajectory with purulent content drainage and pain upon palpation. The animal was initially submitted to surgical drainage of the abscess and to systemic treatment with ceftiofur. In view of the failure of the therapy proposed, the lesion was treated with $2 \%$ papain cream and, subsequently, in association with lyophilized parsley extract (Petroselinum crispum) after the identification of the presence of multi-resistant ESBL producing E. coli, isolated from the lesion and identified through standard laboratory tests. The use of $2 \%$ papain cream reduced the inflammatory process and fibrous tissue. Lyophilized parsley root extract was effective against infection by multi-resistant bacteria.

Discussion: The reduction of purulent secretion and the size of the inflammatory process are due to the proteolytic activity of papain, which decreases bacterial adhesion, and the degree of wound contamination, promoting healing. Several studies have indicated the bacteriostatic and bactericidal activity of papain, but in some trials, this effect was only found in a concentration of $10 \%$ for Pseudomonas aeruginosa and Staphylococcus aureus, and no effect for E. coli bacteria. In vitro studies have shown that the essential oil of Petroselinum crispum leaves and stems is more effective than the essential oil of seeds against this bacterium. Reports of isolation and bacterial identification of wounds and abscesses of horses present a large amount of microorganisms, but the presence of multi-resistant $E$. coli is uncommon. In other countries, the presence of this bacterium in wounds and other regions has been described in this species. In the Netherlands and Germany, the presence of ESBL producing E. coli in horses was detected in clinical samples of pus, stomach, uterus, feces and synovial fluid, presenting a real risk of human contamination by these resistant bacteria. In this sense, the study of antimicrobial agents has great scope, being a crucial point in several sectors of the pharmaceutical field. The phytotherapeutic association, used in this case, represents a possible promising, low-cost alternative for the treatment of contaminated wounds, emphasizing the importance of studies involving alternative treatments for bacterial resistance.
\end{abstract}

Keywords: parsley, lyophilized extract, Escherichia coli, protease, bacterial resistance. 


\section{INTRODUÇÃO}

Devido à resistência bacteriana aos antibióticos convencionais, a pesquisa de produtos naturais que apresentam atividade antibacteriana ou bactericida vem se tornando cada vez mais frequente [16].

Nos últimos anos, a frequência de isolamento de membros da família Enterobacteriaceae resistentes, incluindo a Escherichia coli, aumentou significativamente, destacando-se a presença das beta-lactamases de espectro estendido (ESBL), enzimas capazes de hidrolisar o anel beta-lactâmico de penicilinas, cefalosporinas e monobactâmicos, porém sensíveis ao clavulanato [15].

A presença de E. coli produtora de ESBL em equinos foi verificada em diferentes países, incluindo o Brasil [21].

A papaína, proveniente do látex do mamoeiro (Carica papaya), vem sendo frequentemente empregada no tratamento de feridas em humanos e animais, principalmente por sua capacidade de proteólise, decorrente de enzimas proteolíticas e peroxidases [11], degradando o tecido desvitalizado e necrosado que retardam a cicatrização [17].

Os compostos fenólicos e os flavonóides, como a apigenina, apin, 6-acetylapina eapiol fazem parte dos compostos ativos mais importantes e estudados no extrato de salsa (Petroselinum crispum), com diversas propriedades farmacológicas, como diurética, antioxidante e antimicrobiana [5].

O objetivo deste trabalho é relatar o uso da papaína e extrato de Petroselinum crispum, em um equino com abscesso infectado por E. coli multirresistente produtora de ESBL.

\section{CASO}

Foi encaminhado ao Hospital Veterinário da Universidade Paranaense (UNIPAR), um equino de quatro anos e meio de idade pesando $400 \mathrm{~kg}$, macho, castrado, sem raça definida (SRD), apresentando aumento de volume na face lateral esquerda do terço médio do pescoço, com tempo de evolução de aproximadamente um ano, sendo a causa provável uma injeção intramuscular no músculo esplênio realizada pelo tutor do animal, que não se recordou de qual fármaco fora aplicado. Ao exame físico observou-se lesão característica de abscesso que envolvia o tecido subcutâneo e muscular, com aproximadamente $10 \mathrm{~cm}$ de diâmetro e que apresentava trajeto fistuloso com drenagem de conteúdo purulento e dor à palpação (Figura 1A).
O animal já havia recebido tratamento prévio desde o surgimento do abscesso, com antibióticos a base de benzilpenicilina procaína e limpeza da região com água oxigenada e iodopovidona tópico, sem resultados satisfatórios.

Inicialmente, instituiu-se antibioticoterapia com ceftiofur $\left(\text { Topcef }{ }^{\circledR}\right)^{1}$ na dosagem de $4 \mathrm{mg} / \mathrm{kg}$, por via intramuscular (IM), uma vez ao dia (SID), durante 10 dias, além da drenagem diária do conteúdo do abscesso e lavagem do mesmo com solução fisiológica através de sonda $\mathrm{n}^{\circ} 4$ introduzida pelo canal fistuloso pré-existente (Figura 1 B) o qual não demonstrou eficácia, porém foi capaz de reduzir a quantidade de secreção purulenta. Optou-se então pelo desbridamento cirúrgico da lesão. Após jejum de 24 h, o animal foi submetido à sedação com xilazina $10 \%\left(\operatorname{Sedomin}^{\circledR}\right)^{2}$ na dose de $1 \mathrm{mg} / \mathrm{kg}$ e anestesia infiltrativa local com lidocaína $2 \%\left(\text { Lidovet }^{\circledR}\right)^{3}$, totalizando $10 \mathrm{~mL}$. Em seguida realizou-se curetagem intralesional, através de incisão cirúrgica em face craniodorsal da lesão, criando-se uma abertura oposta à fístula caudoventral pré-existente. No pós-operatório instituiu-se antibioticoterapia com ceftiofur durante 5 dias, na mesma dosagem e posologia descritas anteriormente. Houve melhora significativa, com importante redução da secreção purulenta, porém esta retornou após a interrupção da administração do antibiótico.

Realizou-se o isolamento bacteriano a partir da secreção colhida do abscesso, através de lavagem intralesional com solução fisiológia estéril, utilizando sonda $\mathrm{n}^{\circ}$ 4 e seringa de $20 \mathrm{~mL}$ também estéreis (Figura 1D), com posterior incubação de forma rotineira. A cultura obtida foi submetida ao isolamento de colônias resistentes aos beta-lactâmicos e quinolonas, respectivamente.

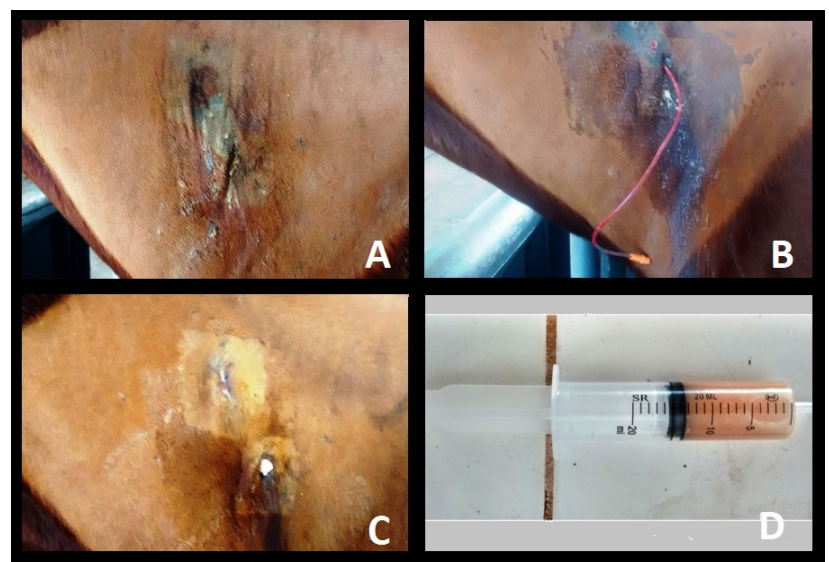

Figura 1. A- Aspecto inicial do abscesso, apresentando drenagem de secreção purulenta através de canal fistuloso na região ventral da lesão. BProcedimento curativo com drenagem de secreção e lavagem do abscesso com solução fisiológica via sonda. C- Abscesso após início da terapia com creme não iônico de papaína, que era depositado com auxílio de sonda através da abertura ventral da lesão. D- Aspecto do material colhido e enviado para isolamento bacteriano. 
A identificação bioquímica das bactérias pertencentes à família Enterobacteriaceae foi realizada por meio do kit para enterobactérias $\left(\mathrm{Newprov}^{\circledR}\right)^{4}$, segundo recomendações do fabricante, identificando-se a bactéria Escherichia coli. Para determinar o perfil de resistência bacteriana, foi utilizado o método de disco-difusão em ágar, segundo recomendações do Clinical and Laboratory Standards Institute (CLSI) [3], por meio do qual detectou-se a multirresistência da bactéria isolada às quinolonas, penicilinas e cefalosporinas, bem como resistência intermediária a aminoglicosídeos.

O teste fenotípico para detecção de cepas produtoras de ESBL foi realizado de acordo com protocolo já padronizado [2].

Optou-se pela realização de tratamento alternativo, com aplicação intralesional de $20 \mathrm{~g}$ de creme contendo extrato de papaína $(20 \mathrm{mg} / \mathrm{g})$, selecionando-se uma base não iônica para o creme, preparado de acordo com a técnica descrita na literatura [6]. As aplicações foram realizadas a cada $12 \mathrm{~h}$, durante sete dias (Figura 1C). Observou-se diminuição do processo inflamatório e do tecido fibroso, já que, no início do tratamento, a lesão apresentava cerca de $10 \mathrm{~cm}$ de diâmetro e, ao final dos sete dias de aplicação do creme, a mesma apresentava cerca de $2 \mathrm{~cm}$ de diâmetro, retornando, quase que completamente, ao formato anatômico normal. Porém, através de nova cultura e antibiograma, contatou-se, ainda, o crescimento da bactéria já descrita.

Optou-se, então, pela inclusão do extrato liofilizado de raiz de salsa (P. crispum), na concentração de $2 \%$, ao creme não iônico a base de papaína. A atividade antimicrobiana do extrato de salsa foi determinada pelo método de microdiluição em caldo com determinação da Concentração Inibitória Mínima (CIM) [13], sendo necessária a concentração de 20 $\mathrm{mg} / \mathrm{mL}$ para a inibição da $E$. coli.

As aplicações foram realizadas, da mesma forma já descrita, durante 20 dias. Ao final deste período, a lesão apresentou ausência de secreção e de trajeto fistuloso, além de completa cicatrização cutânea. $\mathrm{O}$ animal foi observado por mais 30 dias, sem apresentar recidiva, e então recebeu alta.

\section{DISCUSSÃO}

A diminuição da secreção purulenta e do tamanho do processo inflamatório deve-se à atividade proteolítica da papaína, que diminui a adesão das bactérias, e o grau de contaminação da ferida, pro- movendo a cicatrização [19]. Vários estudos indicam a atividade bacteriostática e bactericida da papaína, porém em alguns ensaios este efeito só foi constatado em concentração de $10 \%$, para $P$. aeruginosa e $S$. aureus, e nenhum efeito sob a bactéria E. coli [11]. Isto corrobora com os resultados obtidos neste estudo, pois a papaína na concentração de $2 \%$ não foi capaz de debelar a infecção.

Estudos in vitro mostram que o óleo essencial das folhas e talos da $P$. crispum é mais efetivo, do que o óleo essencial das sementes, contra Escherichia coli e Staphylococcus aureus [10], sendo os extratos aquosos e hidroalcoólicos, das partes aéreas da planta fresca, os mais relatados quanto à inibição desses microorganismos [22]. A atividade antibacteriana do extrato foi atribuída às furocoumarinas como: psoralen, 8-metoxipsoralen, 5-methoxypsoralen, oxypeucedanin e isopipinelin [9] capazes de inibir o crescimento de bactérias como a E. coli e Listeria monocytogenes [20]. Em um estudo pesquisadores avaliaram, in vitro, o extrato aquoso e hidroalcoólico de raízes secas de P. crispum, relatando a atividade bacteriostática e/ou bactericida frente à Escherichia coli e Staphylococcus aureus [16]. Esta pesquisa reforça cientificamente os resultados encontrados no caso relatado.

Recentemente tem se relatado a reversão da resistência a antimcrobianos de algumas bactérias (reverse antibiotic resistance). Neste sentido, uma pesquisa foi realizada com bactérias resistentes à quinolona, utilizando diversas flavonas. Dentre elas, a apigenina mostrou atividade antimicrobiana mais evidente contra as estirpes resistentes à quinolona, em comparação às quinolonas-suscetíveis [12]. O estudo sugere que isso pode abrir novas frentes para a terapia antimicrobiana, diminuindo o problema do ciclo vicioso causado pelo emprego de fármacos e desenvolvimento de resistência aos mesmos.

Ainda neste mesmo sentido, outros pesquisadores avaliaram o efeito antibacteriano e a sinérgica dos flavonóides, apigenina, quercetina, naringenina e ceftazidima em uso isolado e em combinação, contra cepas de Enterobacter cloaca resistentes à ceftazidima [8]. Estes autores verificaram que a apigenina e a naringenina tiveram efeito sinérgico com a ceftazidima para reverter a resistência bacteriana a esta cefalosporina, podendo envolver três mecanismos de ação: a inibição da síntese do peptidoglicano, da atividade de enzimas -lactamase, e pela alteração da permeabilidade e inte- 
gridade da membrana bacteriana. Este último efeito foi comprovado em um estudo que revelou que a adesão e fusão de apigenina lipossomal causam perturbação da membrana através da geração de espécies reativas de oxigênio [1].

Os relatos de isolamento e identificação bacteriana de feridas e abscesso de equinos apresentam uma grande quantidade de micro-organismos, sendo pouco comum a presença de E. coli multirresistente. Autores descreveram cepas bacterianas multirresistentes isoladas de feridas de equinos, sendo elas Acinetobacter baumannii, Hafnia alvei, Proteus mirabilis e Salmonella typhi [18]. Também há relato do isolamento de Actinomyces denticolens em abscesso subcutâneo nesta espécie [4]. A ocorrência de E. coli multirresistente em equinos tem sido detectada principalmente em amostras fecais, sendo sua presença em abscessos não muito estudada.

Em outros países a presença desta bactéria em feridas e outras regiões têm sido descrita. Na Holanda e Alemanha a presença de E. coli produtora de ESBL em cavalos foi detectada em amostras clínicas de pús, estômago, útero, fezes e líquido sinovial [21]. Este é um fato preocupante, visto que esses animais possuem contato muito próximo aos humanos e podem atuar como reservatório para bactérias produtoras de ESBL. Além disso, o difícil manejo de infecções multirresistentes representa risco à saúde animal, bem como, prejuízos financeiros.

Neste sentido, o estudo de agentes antimicrobianos tem grande abrangência, sendo ponto crucial em vários setores do campo farmacêutico [14]. Esses compostos isolados de plantas podem agir como reguladores do metabolismo intermediário, ativando ou bloqueando atividades enzimáticas, seja em nível nuclear ou ribossomal, ou mesmo alterando estruturas de membranas [7].

Desta forma, os resultados obtidos neste estudo reforçam os benefícios do emprego da papaína em feridas, e também comprova a atividade bactericida do extrato de salsa in situ, que juntamente com outras substâncias bioativas podem proporcionar uma alternativa de baixo custo contra enfermidades causadas por bactérias multirresistentes, além da possibilidade de se associar com drogas antibióticas para melhorar o espectro de ação e reduzir a resistência bacteriana frente aos antimicrobianos utilizados na prática clínica.

\section{CONCLUSÃO}

De acordo com os parâmetros avaliados neste caso, conclui-se que a utilização de creme de papaína $2 \%$ diminuiu o processo inflamatório e o tecido fibroso e que o extrato liofilizado de raiz de salsa (P. crispum) foi eficaz contra a infecção pela bactéria Escherichia coli multirresistente, produtora de ESBL, em abscesso em equino. Essa associação pode ser uma alternativa promissora, e de baixo custo, para o tratamento de feridas contaminadas, nesta espécie.

\section{MANUFACTURERS}

${ }^{1}$ Eurofarma Laboratórios S. A., Ribeirão Preto, SP, Brazil.

${ }^{2}$ König do Brasil Ltda. Mairinque, SP, Brazil.

${ }^{3}$ Laboratório Bravet Ltda. Engenho Novo, RJ, Brazil.

${ }^{4}$ Newprov Produtos Para Laboratórios. Pinhais, PR, Brazil.

Declaration of interest. The authors report no conflicts of interest. The authors alone are responsible for the content and writing of the paper.

\section{REFERENCES}

1 Banerjee K., Banerjee S., Das S. \& Mandal M. 2015. Probing the potential of apigenin liposomes in enhancing bacterial membrane perturbation and integrity loss. Journal of Colloid and Interface Science. 453: 48-49.

2 Brun-Buisson C., Legrand P., Philippon A., Montravers F., Ansquer M. \& Duval J. 1987. Transferable enzymatic resistance to third-generation cephalosporins during nosocomial outbreak of multiresistant Klebsiella pneumoniae. Lance. 2(8554): 302-306.

3 CLSI-Clinical and Laboratory Standards Institute. 2013. Performance standards for antimicrobial susceptibility testing: twenty-second informational supplement. CLSI - M100-S22 v. 32. Wayne: CLSI, 184p.

4 Feary D.J., Abraham S., Woolford L. \& Trott D.J. 2013. Identification of Actinomyces denticolens as a cause of a soft tissue abscess in a horse. Australian Veterinary Journal. 91(10): 416-417.

5 Farzei M.H., Abbasabadi Z., Ardekani M.R., Rahimi R. \& Farzaei F. 2013. Parsley: a review of ethnopharmacology, phytochemistry and biological activities. Journal of Traditional Chinese Medicine. 33(6): 815-826.

6 Formulário Nacional da Farmacopéia Brasileira. 2012. 2.ed. São Paulo: Anvisa, 225p.

7 Gonçalves A.L., Alves Filho A. \& Menezes H. 2005. Estudo comparativo da atividade antimicrobiana de extratos de algumas árvores nativas. Arquivos do Instituto Biológico. 72(3): 353-358. 
8 Griangsak E. \& Somnuk C. 2013. Synergistic activity and mechanism of action of ceftazidime and apigenin combination against ceftazidime-resistant Enterobacter cloacae. Phytomedicine. 20(3-4): 262-269.

9 Manderfield M.M., Schafer H.W., Davidson P.M. \& Zottola E.A. 1997. Isolation and identification of antimicrobial furocoumarins from parsley. Journal of Food Protectection. 60(1): 72-77.

10 Minija J. \& Thoppil J.E. 2003. Studies on essential oil composition and microbicidal activities of two South Indian spices of the Apiaceae. International Journal of Aromatherapy. 12(4): 213-215.

11 Monetta L. 1987. Uso da papaína nos curativos feitos pela enfermagem. Revista Brasileira de Enfermagem. 40(1): 66-73.

12 Morimoto Y., Baba T., Sasaki T. \& Hiramatsu K. 2015. Apigenin as an anti-quinolone-resistance antibiotic. International Journal of Antimicrobial Agents. 46(6): 666-673.

13 NCCLS-National Commitee for Clinical Laboratory Standards. Reference Method for broth diluition antifungal susceptibility testing of yeast standard. 2002. 2nd edn. 22(15): 30p.

14 Ostrosky E.A., Mizumoto M.K., Lima M.E.L, Kaneko T.M., Nishikawa S.O. \& Freitas B.R. 2008. Métodos para a avaliação da atividade antimicrobiana e determinação da concentração mínima inibitória (CMI) de plantas medicinais. Revista Brasileira de Farmacognosia. 18(2): 301-307.

15 Peirano G., Asensi M.D., Pitondo-Silva A. \& Pitout J.D. 2011. Molecular characteristics of extended-spectrum $\beta$-lactamase-producing Escherichia coli from Rio de Janeiro, Brazil. Clinical Microbiology and Infection. 17(7): 10391043.

16Primak L.M.S., Bovo F., Pittner E., Monteiro M.C. \& Perez E. 2013. Avaliação da atividade antibacteriana de diferentes extratos de raiz de salsa. Revista de Ciências Médicas e Biológicas. 12(1): 94-100.

17 Sanchez Neto R., Barone B., Teves D.C. Simões M.J., Novo N.F. \& Juliano Y. 1993. Aspectos morfológicos e morfométricos da reparação tecidual de feridas cutâneas de ratos com e sem tratamento com solução de papaína a $2 \%$. Acta Cirúrgica Brasileira. 8(1): 18-23.

18 Sfaciotte R.A.P., Bordin J.T., Vignoto V.K.C., Heller L.M., Pinto A.A, Munhoz P.M., Barbosa M.J.B. \& Wosiacki S.R. 2014. Descrição de cepas bacterianas multirresistentes isoladas de equinos. Revista de Ciência Veterinária e Saúde Pública. 1(1): 077.

19 Vieira R.H., Rodrigues D.P., Gonçalves F.A., Menezes F.G., Aragão J.S. \& Souza O.V. 2001. Microbicidal effect of medicinal plant extracts (Psidium guajava Linn. and Carica papaya Linn.) upon bacteria isolated from fish muscle and known to induce diarrhea in children. Revista do Instituto de Medicina Tropical de São Paulo. 43(3): 145-148.

20 Viuda-Martos M., Mohamady M.A., Fernández-López J., ElRazik K.A.A., Omer E.A., Pérez-Alvarez J.A. \& Sendra E. 2011. In vitro antioxidant and antibacterial activities of essentials oils obtained from Egyptian aromatic plants. Food Control. 22(11): 1715-1722.

21 Vo A.T., Van Duijkeren E., Fluit A.C. \& Gaastra W. 2007. Characteristics of extended-spectrum cephalosporinresistant Escherichia coli and Klebsiella pneumoniae isolates from horses. Veterinary Microbiology. 124(3-4): 248-255.

22 Wong P. \& Kitts D.D. 2006. Studies on the dual antioxidant and antibacterial properties of parsley (Petroselinum crispum) and cilantro (Coriandrum sativum) extracts. Food Chemistry. 97(3): 505-515. 